\title{
Hereditary motor and autonomic neuronopathy 1 maps to chromosome 20q13.2-13.3
}

W. Marques Jr. ${ }^{1}$, M.B. Davis ${ }^{4}$, P.M. Abou-Sleiman ${ }^{4}$, V.D. Marques ${ }^{1}$ W.A. Silva Jr. ${ }^{2,3}$, M.A. Zago ${ }^{2}$, C.S. Sobreira ${ }^{1}$ and A.A. Barreira ${ }^{1}$

\author{
${ }^{1}$ Departamento de Neurologia, ${ }^{2}$ Centro de Terapia Celular, \\ Departamento de Clínica Médica, and ${ }^{3}$ Departamento de Genética, \\ Faculdade de Medicina de Ribeirão Preto, Universidade de São Paulo, \\ Ribeirão Preto, SP, Brasil \\ ${ }^{4}$ Neurogenetics Unit, Institute of Neurology, University College London, \\ London, UK
}

Correspondence

W. Marques Jr.

Departamento de Neurologia

FMRP, USP

Av. Bandeirantes, 3900

14049-900 Ribeirão Preto, SP

Brasil

Fax: +55-16-602-3307

E-mail: wmjunior@fmrp.usp.br

Research supported by FAPESP (No. 03/00424-3), Secretaria de Saúde do Estado de São Paulo and FAEPA.

Received August 20, 2004 Accepted September 30, 2004 $\ldots \ldots \ldots \ldots \ldots \ldots \ldots$

\begin{abstract}
The spinal muscular atrophies (SMA) or hereditary motor neuronopathies result from the continuous degeneration and death of spinal cord lower motor neurons, leading to progressive muscular weakness and atrophy. We describe a large Brazilian family exhibiting an extremely rare, late-onset, dominant, proximal, and progressive SMA accompanied by very unusual manifestations, such as an abnormal sweating pattern, and gastrointestinal and sexual dysfunctions, suggesting concomitant involvement of the autonomic nervous system. We propose a new disease category for this disorder, 'hereditary motor and autonomic neuronopathy', and attribute the term, 'survival of motor and autonomic neurons 1' (SMAN1) to the respective locus that was mapped to a $14.5 \mathrm{cM}$ region on chromosome $20 \mathrm{q} 13.2-13.3$ by genetic linkage analysis and haplotype studies using microsatellite polymorphic markers. This locus lies between markers D20S120 and D20S173 showing a maximum LOD score of 4.6 at D20S171, defining a region with 33 known genes, including several potential candidates. Identifying the SMAN1 gene should not only improve our understanding of the molecular mechanisms underlying lower motor neuron diseases but also help to clarify the relationship between motor and autonomic neurons.
\end{abstract}

Key words

- Spinal muscular atrophy

- Hereditary motor neuronopathies

- Autonomic neuropathies

\section{Introduction}

The spinal muscular atrophies (SMA) are hereditary diseases characterized by progressive muscular weakness and atrophy due to degeneration and death of the lower motor neurons (1). Adult types of proximal SMAs, with onset after the age of 15 , are uncommon and heterogenous, exhibiting X-linked, au- tosomal recessive or autosomal dominant inheritances (2). Although rare, autosomal dominant, adult-onset, proximal SMAs have been reported by various authors. Quarfordt et al. (3) described a family with autosomal dominant, type II hyperlipoproteinemia in which four dyslipidemic brothers also displayed a predominantly proximal weakness of neurogenic origin. Apparently, the mother 
was also affected, but the status of their children could not be determined, as these were still too young to manifest the disease. Zatz et al. (4) described a Brazilian family of Italian origin who developed a disease characterized by onset between 28 to 62 years of age, and an interval from onset to death ranging from 3 months to 1 year. Bundey and Lovelace (5) also described a family exhibiting autosomal dominant inheritance, lateonset and slowly progressive weakness without sensory manifestations. Pearn (6) described three relatives exhibiting an onset ranging from 26 to 46 years.

In 1962, Finkel (7) described a Brazilian family with a "late-onset, pseudomyophatic form of a heredofamilial progressive muscular atrophy". Based on the presence of fasciculations, Finkel considered a neurogenic origin, and interpreted the lineage findings as suggestive of recessive inheritance, a conclusion later modified. Richieri-Costa et al. (8) reviewed this family in 1981 and described a second family in the same geographical area. These investigators performed electrophysiological and morphological studies which confirmed the neurogenic origin of the condition, which was then termed Finkel's disease (MIM 182980) (9). They also noted other important manifestations of the disorder, such as a prominent abdomen and occasional episodes of choking.

We have recently evaluated 50 members of this large Brazilian family exhibiting adult-onset SMA, whose 16 affected members had not been previously described by Finkel (7) or Richieri-Costa et al. (8). In addition to SMA findings, we have found dyslipidemia, sweating abnormalities, and autonomic disturbances such as bowel and sexual dysfunction. We identified the localization of this disorder to chromosome 20q13.2-q13.3.

\section{Patients and Methods}

Generations IV and V of the family were available for study. A detailed clinical and neurological examination of 50 family members was performed by two of the authors (VDM and WM) in the patients' own homes. Sixteen of the 50 family members evaluated were consistently affected. Five of the affected members were also attended as inpatients, when a complete diagnostic evaluation of their condition was performed, including biochemical analyses, electromyography (EMG), muscle biopsy, and certain autonomic functional tests.

After obtaining informed consent, DNA from the subjects evaluated was extracted from peripheral leukocytes according to standard methods. Deletions in the telomeric survival motor neuron gene (SMN1) were excluded using the PCR-based test described by van der Steege et al. (10). A genome-wide linkage search was performed using 16 affected and 4 unaffected family members who were past the age of disease onset. Linkage was performed using an ABI PRISM ${ }^{\circledR}$ Linkage Mapping Set-HD5 (PE Applied Biosystems, Foster City, CA). Microsatellite markers were amplified from genomic DNA using the PCR technique under conditions specified by the manufacturer, and submitted to denaturing acrylamide gel electrophoresis with a 377 DNA Sequencer (PE Applied Biosystems). Initially, 400 markers with a 10 -cM resolution were genotyped semiautomatically using Genescan and Genotyper software (PE Applied Biosystems).

The genotypes were examined manually and were initially used to construct haplotypes. In the chromosomal region where haplotype reconstruction showed segregation with the disease, additional markers were analyzed. Pairwise LOD scores were generated across this region using the FASTLINK version of the MLINK software (11). Only affected family members were included in the analysis, which employed a disease allele frequency of 0.0001 .

This study was approved by both the Hospital and the national Ethics Committees. 


\section{Results}

Disease onset ranged from the third to the sixth decade. Characteristically, the disease has an axo-rhizomelic distribution, initially affecting the proximal muscles of the lower limbs, then the proximal muscles of the upper limbs, followed by involvement of the distal muscles of all limbs, finally resulting in a severe and generalized weakness with respiratory insufficiency and death. In most cases, severe weakness of the abdominal muscles was also present from the early stages, resulting in a prominent abdomen. The affected muscles are hypotonic, tendon jerks are decreased or absent, Babinski's sign is not part of the disease, and generalized fasciculations are always present. Sensation is normal, as is coordination. Many patients complain of difficulty in swallowing and several suffer from severe constipation. Some patients reported very prolonged erection, possibly owing to late ejaculation, that eventually may be followed by sexual impotence. A generalized hypohidrosis was documented. Most patients have persistent dyslipidemia. EMG findings are consistent with a chronic and progressive generalized impairment of the lower motor neurons. A muscle biopsy revealed a typical neurogenic pattern, confirming the EMG findings.

As shown in Table 1, marker haplotypes on chromosome 20q showed complete segregation with the disease phenotype. Crossing over events in affected family members defined an area of $21.5 \mathrm{cM}$, between markers D20S902 and D20S173 (Figure 1). The maximum LOD score obtained was 4.6 at D20S171 (Table 1).

To refine the identification of the region further, an additional ten microsatellite markers were genotyped in five affected recombinant family members (Table 2). This permitted refining of the localization to a minimum identity region between markers D20S120 and D20S173 (Figure 2) which, according to build 30 of the UCSC Human Genome Project
Working Draft database (12), spans $5.8 \mathrm{Mb}$ and contains 33 known genes and a further 47 predicted genes in a region of $14.5 \mathrm{cM}$.

\section{Discussion}

The SMAs are defined as diseases showing isolated impairment of the lower motor neurons, mainly those located in the ventral horn of the spinal cord. There are, however, some hereditary motor neuropathies/neuronopathies displaying additional features, such as Kennedy's bulbospinal muscular atrophy (MIM 313200) (9) that involves some mild sensory features (13). The disease phenotype we describe here has not been described previously: firstly, it is an autosomal-dominant, late-onset, proximal SMA; secondly, there is an axo-rhizomelic distribution with early impairment of the lower motor neurons innervating the abdominal muscles, and thirdly, besides motor involvement, autonomic manifestations are also present. We propose naming this locus as "survival of motor and autonomic neurons 1" (SMAN1, approved by the HUGO gene Nomenclature Committee) and the disease as "hereditary motor and autonomic neuronopathy 1 ".

The 5.8-Mb candidate region should be refined further by identifying additional recombination events in family members yet untested, and by the use of single nucleotide polymorphisms. Concurrently, promising candidate genes, selected through their expression profiles and function, will be

Table 1. Results of two-point linkage analysis between SMAN1 locus and 20q13.213.3 markers.

\begin{tabular}{lcrrrrrrr}
\hline Markers & \multicolumn{7}{c}{ Recombination fraction } \\
\cline { 2 - 9 } & 0.0 & 0.001 & 0.01 & 0.05 & 0.1 & 0.2 & 0.3 & 0.4 \\
\hline D20S119 & -inf & -4.61 & -1.71 & 0.02 & 0.47 & 0.51 & 0.29 & 0.09 \\
D20S178 & -inf & -1.07 & 0.78 & 1.75 & 1.83 & 1.41 & 0.85 & 0.35 \\
D20S196 & -inf & 0.12 & 1.76 & 2.67 & 2.66 & 2.04 & 1.24 & 0.52 \\
D20S109 & 3.17 & 3.16 & 3.08 & 2.73 & 2.30 & 1.51 & 0.85 & 0.33 \\
D20S171 & 4.60 & 4.59 & 4.49 & 4.02 & 3.45 & 2.36 & 1.39 & 0.60 \\
D20S173 & -0.07 & 1.41 & 2.30 & 2.57 & 2.34 & 1.66 & 0.98 & 0.41
\end{tabular}


Figure 1. Haplotype analysis of the affected family members. The haplotypes associated with the disease are in bold. Recombination events are identified by horizontal bars that delineate the involved area of chromosome 20q13.2-20q13.3.
Table 2. Haplotype and genotypic analysis of ten additional markers in five family members in whom a recombination event had been previously identified.

\begin{tabular}{|c|c|c|c|c|c|c|c|c|c|c|c|}
\hline \multirow{3}{*}{$\begin{array}{l}\text { Markers } \\
\text { D20S183 }\end{array}$} & \multicolumn{10}{|c|}{ Haplotype analysis } & \multirow{3}{*}{$\begin{array}{r}\text { kbp } \\
51738\end{array}$} \\
\hline & \multicolumn{2}{|c|}{ IV7 } & \multicolumn{2}{|c|}{ IV46 } & \multicolumn{2}{|c|}{ IV53 } & \multicolumn{2}{|c|}{ V5 } & \multicolumn{2}{|c|}{ V12 } & \\
\hline & 1 & 1 & 3 & 2 & 4 & 2 & 1 & 1 & 1 & 1 & \\
\hline D20S913 & 3 & 2 & 3 & 4 & 1 & $\overline{2}$ & 1 & 1 & 4 & 2 & 52229 \\
\hline D20S120 & 2 & 1 & 3 & 1 & 2 & 1 & 4 & $\underline{5}$ & 1 & 1 & 52734 \\
\hline D20S468 & 3 & 3 & 2 & 3 & 1 & 3 & 2 & 3 & 3 & 3 & 53187 \\
\hline D20S853 & 2 & 3 & 4 & 3 & 2 & 3 & 2 & 3 & 2 & 3 & 53601 \\
\hline D20S102 & 2 & 1 & 1 & 1 & 1 & 1 & 2 & 1 & 1 & 1 & 54720 \\
\hline D20S158 & 1 & 2 & 1 & 2 & 1 & 2 & 3 & 2 & 4 & 2 & 55317 \\
\hline D20S430 & 3 & 3 & 2 & 3 & 1 & 3 & 2 & 3 & 4 & 3 & 55878 \\
\hline D20S164 & 2 & 1 & 3 & 1 & 5 & 1 & 3 & 1 & 3 & 1 & 56781 \\
\hline D20S443 & 1 & 1 & 1 & 1 & 3 & 1 & 2 & 1 & 2 & 1 & 57223 \\
\hline D20S171 & 5 & 3 & 4 & 3 & 2 & 3 & 3 & 3 & 3 & 3 & 57536 \\
\hline D20S173 & 3 & 3 & 2 & 2 & 2 & 2 & 1 & 2 & 2 & 2 & 58606 \\
\hline
\end{tabular}

Recombination events on markers D20S183, D20S913 and D20S120, identified by a horizontal bar, define a minimum region of $14.5 \mathrm{cM}$ and $5.8 \mathrm{Mb}$ between markers D20S120 and D2S173. The haplotypes associated with the disease are in bold. 
screened for mutations. There are at least 33 known genes and 23 predicted genes in the mapped region, making the selection difficult. Among the first candidates we have chosen, Syntaxin 16 (STX16) (MIN 603666) seems to selectively regulate Golgi dynamics, vesicle-associated membrane proteinassociated protein $\mathrm{B}(V A P B)$ has a role in vesicle trafficking, and endothelin 3 (EDN3) (MIM 131242) is essential in the development of neural crest-derived cell lineages and has been reported to cause hereditary autonomic disorders.

The SMAN1 gene function must be important for both motor and autonomic neurons, but not for sensory neurons. Although no similar pattern of disease has been described, the function of the putative gene may be similar to that of those genes known to be involved in motor neuron disorders, like the survival of motor neuron gene SMN1 (MIM 600354) (9), which is mutated in SMA (14). Alternatively, the gene may code for one of the various proteins known to interact with SMN1. SMN1 is a ubiquitously expressed protein which shows no significant homology to any other protein and which associates with various other proteins to form a large complex implicated in the function of the spliceosome (15). SMN1 also interacts directly with apoptotic proteins (16) RNA, RNA polymerases and RNA helicases (17). Mutations in $\mathrm{Cu}, \mathrm{Zn}$-superoxide dismutase (SOD1, MIM 147450) (9) account for approximately $20 \%$ of familial amyotrophic lateral sclerosis, a motor neuron disorder that results from dysfunction of both upper and lower motor neurons, without autonomic involvement. Recently, it has been proposed that these mutations may significantly decrease the anti-apoptotic effects of certain heat shock proteins (18). The Alsin gene (MIM 606352) (9) is mutated in recessive amyotrophic lateral sclerosis 2, a disorder with prominent upper motor neuron impairment without autonomic dysfunction $(19,20)$, a pattern different from that seen in this family. Many genes are now known to be implicated in hereditary motor and sensory neuropathies (21), although in all there is clear clinical and/or neurophysiological involvement of the sensory fibers. Similarly, the genes for some of the hereditary sensory and autonomic diseases (HSAN) have now been identified, including SPTLC for HSAN 1 (MIM 605712), IKBKAP for HSAN 3 (MIM 603722), and TRKA/NGF receptor for HSAN 4 (MIM 191315) (9); however, all have important sensory manifestations. To conclude, there is no good prototype for the SMAN1 gene since mutations in all known genes associated with lower motor neuron loss or autonomic dysfunction result in a notably distinct phenotype.

Identifying the causative gene will not only allow accurate genetic counseling and diagnosis of this disease, but will also contribute to our understanding of the molecular mechanisms underlying both lower motor neurons and autonomic neuron disorders.

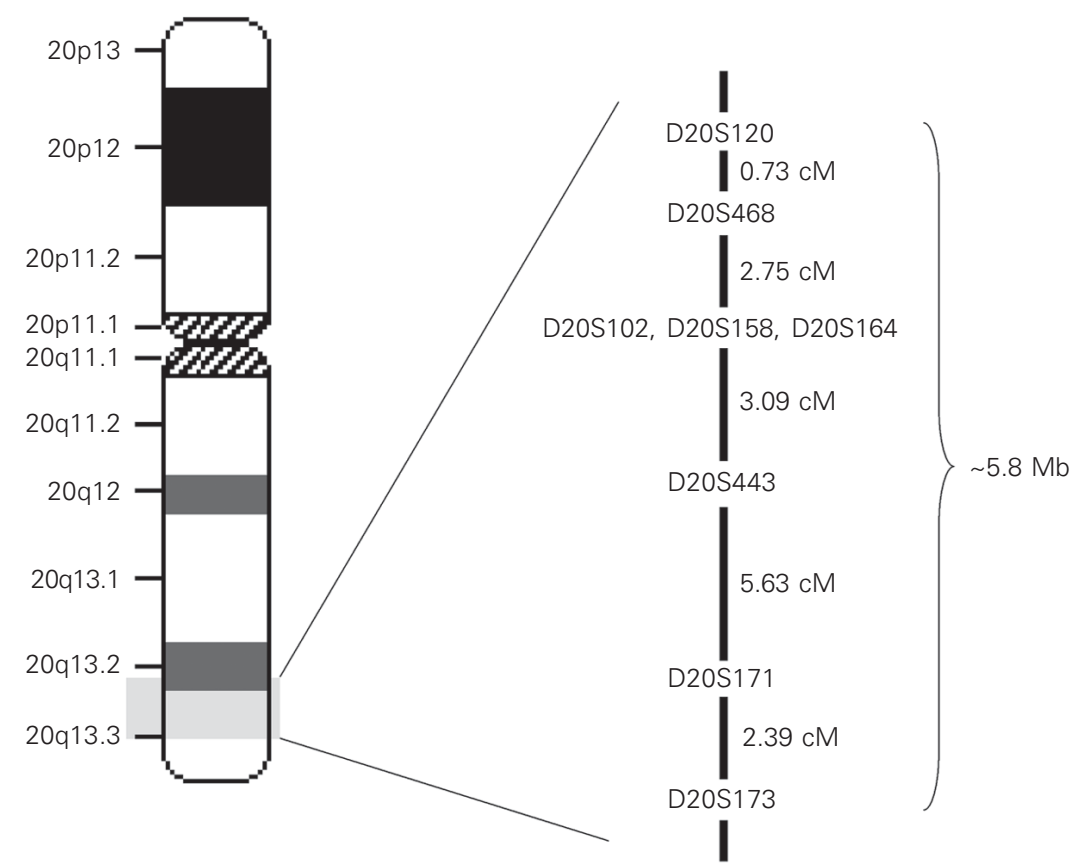

Figure 2. Genetic map of the SMAN1 locus on chromosome 20q13.2-13.3. Location of genetic markers (cM) were obtained from MapView (http://www.ncbi.nlm.nih.gov/ mapview). 


\section{References}

1. Wang $\mathrm{CH}$ (2003). The molecular genetic basis of spinal muscular atrophies. In: Rosenberg RN, Prusiner SB, DiMauro S, Barchi RL \& Nestler EJ (Editors), The Molecular and Genetic Basis of Neurologic and Psychiatric Disease. 3rd edn. Butterworth Heinemann, Philadelphia, PA, USA, 455-466.

2. Baraitser M (1997). The Genetics of Neurological Disorders. 3rd edn. Oxford University Press, Oxford, UK.

3. Quarfordt SH, DeVivo DC, Engel WK, Levy RI \& Fredrickson DS (1970). Familial adult-onset proximal spinal muscular atrophy. Report of a family with type II hyperlipoproteinemia. Archives of Neurology, 22: 541-549.

4. Zatz M, Penha-Serrano C, Frota-Pessoa O \& Klein D (1971). A malignant form of neurogenic muscular atrophy in adults, with dominant inheritance. Journal de Genetique Humaine, 19: 337-354.

5. Bundey S \& Lovelace RE (1975). A clinical and genetic study of chronic proximal spinal muscular atrophy. Brain, 98: 455-472.

6. Pearn J (1978). Autosomal dominant spinal muscular atrophy: a clinical and genetic study. Journal of Neurological Sciences, 38: 263-275.

7. Finkel N (1962). A forma pseudomiopática tardia da atrofia muscular progressiva heredo-familial. Arquivos de Neuropsiquiatria, 20: 307322.

8. Richieri-Costa A, Rogatko A, Levisky R, Finkel N \& Frota-Pessoa O (1981). Autosomal dominant late adult spinal muscular atrophy, type Finkel. American Journal of Medical Genetics, 9: 119-128.

9. Online Mendelian Inheritance in Man (OMIM) ${ }^{\mathrm{TM}}$. Johns Hopkins University, Baltimore, MD, USA. MIM Number 182980 for Finkel's disease, 600354 for SMN1, 313200 for Kennedy's disease, 603666 for STX16, 605704 for VAPB, 131242 for EDN3, 147450 for SOD1, 606352 for Alsin, 605712 for SPTLC1, 603722 for IKBKAP, and 191315 for TRK1. [http://www.ncbi.gov/Omim/]. Accessed in July 2004.

10. van der Steege SG, Grootscholten PM, van der Vlies $P$, Draaijers TG, Osinga J, Cobben JM, Scheffer H \& Buys CH (1995). PCRbased DNA test to confirm clinical diagnosis of autosomal reces- sive spinal muscular atrophy. Lancet, 345: 985-986.

11. Lathrop GM \& Lalouel JM (1984). Easy calculations of lod scores and genetic risks on small computers. American Journal of Human Genetics, 36: 460-465.

12. USSC Human Genome Project Working Draft, http://genome.ucsc. edu (for choosing the microsatellite markers on chromosome 20q).

13. Olney RK, Aminoff MJ \& So YT (1991). Clinical and electrodiagnostic features of $X$-linked recessive bulbospinal neuronopathy. Neurology, 41: 823-828.

14. Lefebvre S, Burglen L, Reboullet S, Clermont O, Burlet P, Viollet L, Benichou B, Cruaud C, Millasseau P \& Zeviani M (1995). Identification and characterization of a spinal muscular atrophy-determining gene. Cell, 80: 155-165.

15. Liu Q \& Dreyfuss G (1996). A novel nuclear structure containing the survival of motor neurons protein. EMBO Journal, 15: 3555-3565.

16. Iwahashi $H$, Eguchi $Y$, Yasuhara N, Hanafusa $T$, Matsuzawa $Y$ \& Tsujimoto $Y$ (1997). Synergistic anti-apoptotic activity between Bcl2 and SMN implicated in spinal muscular atrophy. Nature, 390: 413417.

17. Pellizzoni L, Charroux B, Rappsilber J, Mann M \& Dreyfuss G (2001). A functional interaction between the survival motor neuron complex and RNA polymerase II. Journal of Cell Biology, 152: 75-85.

18. Okado-Matsumoto A \& Fridovich I (2002). Amyotrophic lateral sclerosis: a proposed mechanism. Proceedings of the National Academy of Sciences, USA, 99: 9010-9014.

19. Hadano S, Hand CK, Osuga $H$ et al. (2001). A gene encoding a putative GTPase regulator is mutated in familial amyotrophic lateral sclerosis 2. Nature Genetics, 29: 166-173.

20. Yang $Y$, Hentati A, Deng HX et al. (2001). The gene encoding alsin, a protein with three guanine-nucleotide exchange factor domains, is mutated in a form of recessive amyotrophic lateral sclerosis. Nature Genetics, 29: 160-165.

21. Boerkoel CF, Takashima H, Garcia CA et al. (2002). Charcot-MarieTooth disease and related neuropathies: mutation distribution and genotype-phenotype correlation. Annals of Neurology, 51: 190-201. 